\title{
Microscopic Phase Structure of Mo-based Catalyst and Its Catalytic Activity for Soot Oxidation
}

\author{
Congwei Mei ${ }^{1}$, Yinnan Yuan ${ }^{1,2}$, Xianming Li $^{1}$, Deqing $\mathrm{Mei}^{1^{*}}$ \\ ${ }^{1}$ School of Automobile and Traffic Engineering, Jiangsu University, Zhenjiang, \\ Jiangsu 212013, China \\ ${ }^{2}$ School of Energy, Soochow University, Suzhou, Jiangsu 215006, China
}

Received: 19th July 2016; Revised: 30th August 2016; Accepted: 9th September 2016

\begin{abstract}
The $\mathrm{MoO}_{3}$ catalysts supported on nano-scale $\mathrm{TiO}_{2}$ with various loading rates $(5 \%, 10 \%, 20 \%$, and $40 \%$ ) were prepared by an impregnation method. The phase structures of nano-scale $\mathrm{MoO}_{3} / \mathrm{TiO}_{2}$ catalysts were characterized by Brunner-Emmet-Teller, Fourier Transform Infrared Spectra, X-ray Diffraction, and Scanning Electron Microscope. The oxidation activities of catalysts over diesel soot were performed in a Thermogravimetric Analysis system. The kinetics of the catalytic oxidation process was analyzed based on Starink method. The characterization results showed that the phase structure of $\mathrm{MoO}_{3}$ supported on $\mathrm{TiO}_{2}$ depends heavily on the molybdenum contents, which put great effects on soot oxidation. The orthorhombic crystal system $\left(\alpha-\mathrm{MoO}_{3}\right)$ appeared on the surface of the catalysts when the $\mathrm{MoO}_{3}$ exceeds $10 \%$. Due to the low melting point and good surface mobility of $\mathrm{MoO}_{3}$, the catalytic activity was increased and the characteristic temperatures were decreased with the increase in $\mathrm{MoO}_{3}$ contents. As a result, the activities of catalysts with different loading rates for soot oxidation can be ranked as: Mo5<Mo10<Mo20<Mo40. Via pyrolysis kinetics analysis, it is revealed that Mo40 requires the minimum activation energy for soot oxidation, which fits well with the TG experimental results. In summary, the catalytic activity of $\mathrm{MoO}_{3}$ breaks the threshold effect. Copyright $\odot 2016$ BCREC GROUP. All rights reserved
\end{abstract}

Abstract

Keywords: soot oxidation; nano-scale $\mathrm{MoO}_{3} / \mathrm{TiO}_{2}$ catalysts; Starink method

How to Cite: Mei, C., Yuan, Y., Li, X., Mei, D. (2016). Microscopic Phase Structure of Mo-based Catalyst and Its Catalytic Activity for Soot Oxidation. Bulletin of Chemical Reaction Engineering \& Catalysis, 11 (3): 389-397 (doi:10.9767/bcrec.11.3.608.389-397)

Permalink/DOI: http://doi.org/10.9767/bcrec.11.3.608.389-397

\section{Introduction}

Diesel engines, based on their high combustion efficiency, reliability, adaptability and cost-effectiveness, are widely applied in the heavy truck, coach, engineering machinery, ship, generators, etc. [1]. However, emissions exhausted from diesel engines are still the major environmental problem, although many

* Corresponding Author.

E-mail: meideqing@ujs.edu.cn (D. Mei) measures have been taken to reduce them. Among these, diesel particulate filter (DPF) is of great importance to diminish particulate matters from a diesel engine. Nevertheless, the filter must be regenerated periodically [2,3]. Currently, it has been a research focus to explore the efficient catalyst for soot oxidation with low light-off temperature and long service life.

Recently, different catalysts have been tested for soot oxidation, such as lead, cobalt, vanadium, molybdenum and copper oxides, noble metals, perovskites, etc. [4-6]. Among these 
catalysts, $\mathrm{MoO}_{3}$ seems to be the most promising one. Many scholars found that the contact state between soot and catalysts played a vital role in reactions [7-9]. Toniolo [4] and Leocadio [5] found that the melting point of molybdenumbased catalyst is relatively low, which may lead to a liquid eutectic phenomena under high temperature. Thus, on the carrier surface, the active component $\mathrm{MoO}_{3}$ has high mobility, which can improve the contact of soot with catalysts and then increase the conversion efficiency. With the unique two-dimensional layered structure combined by Van force [10], it is easy to separate a part of oxygen atoms from $\mathrm{MoO}_{3}$, which helps to intensify the oxidation reaction. Furthermore, $\mathrm{MoO}_{3}$ also has a high selectivity in producing carbon dioxide than carbon monoxide in oxidation reactions [6].

The molybdenum catalyst has particular and superior catalytic performance in many fields. As an instance, Li [11] successfully utilized the molybdenum catalyst in the selective oxidation of ethane to aldehydes. Feng [12] found that compared with other catalysts, the molybdenum catalyst is the best one for direct synthesis of mixed alcohols from synthesis gas. However, less research of molybdenum-based catalysts in the DPF regeneration has been done.

In this work, nano-scale $\mathrm{MoO}_{3} / \mathrm{TiO}_{2}$ catalysts with various loading rates were prepared through an impregnation method. The phase structure and surface species of catalysts were characterized through Brunner-Emmet-Teller (BET), Fourier Transform Infrared spectrometer (FT-IR), X-ray Diffraction (XRD), and Scanning Electron Microscope (SEM). The performance of soot oxidation over molybdenum-based catalysts was evaluated through a Thermogravimetric Analysis (TGA). Based on a Strarink method, the quantitative pyrolysis kinetics of soot oxidation over molybdenum-based catalysts was worked out, which helps to explore the catalytic mechanism and to provide a theoretical guidance for its practical application in DPF regeneration.

\section{Experimentals}

\subsection{Preparation of catalysts}

Compared with pure substance of $\mathrm{MoO}_{3}$, the complicated catalyst of $\mathrm{MoO}_{3}$ loading on $\mathrm{TiO}_{2}$ owns excellent sulfur resistance and great specific surface area. Moreover, the easy electron transfer of nano-scale $\mathrm{TiO}_{2}$-anatase can make molybdenum lie in a low chemical valence, which greatly promotes the activity of catalysts. Therefore, in many experiments,
$\mathrm{TiO}_{2}$-anatase has been used as a support of catalyst.

Nano-scale $\mathrm{TiO}_{2}$-anatase produced by Shanghai Aladdin Reagent Co. Ltd. was utilized as the support. The $\mathrm{MoO}_{3}$ is from ammonium molybdate produced by Sinopharm Chemical Reagent Co. Ltd. The complicated $\mathrm{MoO}_{3} / \mathrm{TiO}_{2}$ catalysts with various loading rates of $5 \%, 10 \%, 20 \%$, and $40 \%$ were prepared respectively by an equal volume impregnation method. Correspondingly, these catalysts were named as Mo5, Mo10, Mo20, and Mo40. The various predefined contents of $\mathrm{MoO}_{3}$ were dropped into the precursor solution, and then the $\mathrm{TiO}_{2}$ in fine powder was added to the prehandled solution with a blend ratio of $1 \mathrm{~g} \cdot \mathrm{mL}^{-1}$ according to the water absorption of $\mathrm{TiO}_{2}$. The mixture was oscillated for 30 minutes by an ultrasonic oscillator after uniformly impregnating and stirring, and then it was stored at ambient temperature for 24 hours. Finally, it was dried for 12 hours at the temperature of $110^{\circ} \mathrm{C}$ in an oven and then was calcinated for 6 hours at the temperature of $500{ }^{\circ} \mathrm{C}$ in a box-type resistance furnace.

\subsection{Equipment of experiment}

The specific surface area of the catalyst was tested by NDVA-2000e BET produced by Quantachrome in America. NEXUS-470 FT-IR produced by Nicolet in America was used to determine the chemical composition of catalysts through 32 times scanning. The scanning range was $4000 \sim 400 \mathrm{~cm}^{-1}$ with a resolution of $4 \mathrm{~cm}^{-1}$. The crystalline phases of catalysts were detected by an X-ray diffraction (BRUKER D8 ADVANCE with $\mathrm{Cu}-\mathrm{Ka}$ radiation $-40 \mathrm{kV}, 40 \mathrm{~mA}$ ) with a scanning rate of $4^{\circ} \cdot \mathrm{min}^{-1}$. The microstructure of catalysts was observed by using a JSM-7001F SEM produced by Oxford Instruments (OIMS) in UK.

The experiments of soot oxidation over molybdenum-based catalysts were performed in a TGA/DSC1 thermogravimetric analyzer made by METTLER in Swiss. Printex-U carbon black (Degussa) was used as a substitute of diesel soot in this study due to its similarity to diesel soot in structure constitution as well as the ideal experimental repeatability [14]. Nanoscale molybdenum-based catalysts with low melting point can provide more active sites and reduce the internal diffusion, so the catalysts and soot with a mass ratio of 5:1 were stirred adequately in a beaker. Parameters of thermogravimetric test were set as follows: the reaction gas was air with a flow rate of 50 $\mathrm{mL} \cdot \mathrm{min}^{-1}$, and the sample was heated at a rate 
of $10{ }^{\circ} \mathrm{C} . \mathrm{min}^{-1}$, and the programmed temperature rising range was set as $40 \sim 800{ }^{\circ} \mathrm{C}$, and the weight of the sample was about $4 \mathrm{mg}$.

\subsection{Thermegravimetric kinetics model}

Recently, the iso-conversional method is one of the most widespread methods in thermal kinetics analysis, which can directly give out the activation energy without dynamics model function and thus avoids the errors caused by various assumptions of the reaction mechanism function. So, it can be called as a model-free method. Multiple scanning methods such as Flynn-Wall-Ozawa (FWO), Kissinger-AkahiraSunose (KAS) and Boswell were presented according to different approximate processing method [15-17]. Starink summarized these three typical research results about isoconversional method in recent years and presented Equation (1) [18]:

$$
\ln \left(\frac{\beta}{T_{S}}\right)=-\frac{B E}{R T}+C_{S}
$$

where: $S, B$, and $C_{S}$ are constants; $E$ is the activation energy $\left(\mathrm{kJ} \cdot \mathrm{mol}^{-1}\right) ; R$ is the molar gas constant $\left(8.1345 \mathrm{~J} \cdot(\mathrm{mol} \cdot \mathrm{K})^{-1}\right) ; \quad T$ is the thermodynamic temperature $(\mathrm{K})$; and $\beta$ is the heating rate $\left(\mathrm{K} \cdot \mathrm{min}^{-1}\right)$.

Starink adjusted constants $S$ and $B$ by precisely analyzing temperature integral and then brought out the Equation (2):

$$
\ln \left(\frac{\beta}{T^{1.8}}\right)=-1.0037 \frac{E}{R T}+C_{S}
$$

It was proved that Equation (2) is more accurate than Ozawa, Kissinger and Boswell equations [18]:

$$
\begin{aligned}
& \ln \beta=-1.0516 \frac{E}{R T}+C_{O} \\
& \ln \frac{\beta}{T^{2}}=-\frac{E}{R T}+C_{K} \\
& \ln \frac{\beta}{T}=-\frac{E}{R T}+C_{B}
\end{aligned}
$$

where: $C_{0}, C_{K}$, and $C_{B}$ are constants and represent Ozawa, Kissinger and Boswell respectively. The conversion ratio $(a)$ is defined as:

$$
\alpha=\left[\left(m_{0}-m\right) /\left(m_{0}-m_{\infty}\right)\right] \times 100 \%
$$

where: $m$ is the current mass of sample $(\mathrm{mg})$; $m_{0}$ is the initial mass of sample $(\mathrm{mg})$; and $m_{\infty}$ is the residual mass of sample $(\mathrm{mg})$.

As a consequence, a group of thermodynamic temperatures under different heating rates were revealed by thermogravimetric analysis of soot oxidation under catalysts at each equal conversion ratio. A linear relationship between $\ln \left(\beta / T^{1.8}\right)$ dan $1 / T$ can be expected according to Equation (2). Correspondingly, the average activation energy $(E)$ can be calculated by the slope of the fitted line.

\section{Results and Discussion}

\subsection{Characterization of catalysts}

\subsubsection{Brunner-Emmet-Teller}

The BET results of $\mathrm{MoO}_{3} / \mathrm{TiO}_{2}$ catalysts and $\mathrm{N}_{2}$ adsorption-desorption are shown in Table 1. It is found that both the specific surface area and pore volume of catalysts were reduced with the increase in $\mathrm{MoO}_{3}$ loading rate, because $\mathrm{MoO}_{3}$ is easy to diffuse into micro pores and to make the blockage of micro pores in $\mathrm{TiO}_{2}$ during impregnation and calcination. Besides, with high loading rates, more dense and smooth-faced crystals of $\mathrm{MoO}_{3}$ were formed after roasting. Therefore, the specific surface areas and pore volumes of the catalyst were evidently reduced.

\subsubsection{Fourier Transform Infrared Spectrometer}

Fourier transform infrared spectroscopy has been a qualitative and quantitative widely used technique in industry featuring high sensitivity [19]. It can characterize the components by measuring characteristic infrared absorption bands. The FT-IR spectra of $\mathrm{MoO}_{3}$ catalysts

Table 1. BET specific surface areas and pore volumes of $\mathrm{MoO}_{3} / \mathrm{TiO}_{2}$ catalysts

\begin{tabular}{ccc}
\hline Sample & $\begin{array}{c}S_{B E T} \\
\left(\mathrm{~m}^{2} \cdot \mathrm{g}^{-1}\right)\end{array}$ & $\begin{array}{c}V_{P} \\
\left(\mathrm{~cm}^{3} \cdot \mathrm{g}^{-1}\right)\end{array}$ \\
\hline soot & 71.355 & 0.359 \\
Mo5 & 40.717 & 0.289 \\
Mo10 & 15.704 & 0.104 \\
Mo20 & 3.982 & 0.034 \\
Mo40 & 3.782 & 0.014 \\
\hline
\end{tabular}


with different loading rates are shown in Figure 1.

Through the analysis, there was a very wide and intense band at both sides of $600 \mathrm{~cm}^{-1}$, which is the flexible and variable-angle vibration of $\mathrm{Ti}-\mathrm{O}$ in $\mathrm{TiO}_{2}$-anatase. The vibration band of Ti-O-Ti was at $1384.0 \mathrm{~cm}^{-1}$. The broad vibration bands at $3427.2 \mathrm{~cm}^{-1}$ were flexible vibrations of $\mathrm{Ti}-\mathrm{O}-\mathrm{H}$ on the $\mathrm{TiO}_{2}$ surface and $\mathrm{H}-\mathrm{O}-\mathrm{H}$ in the absorbed water. At the same time, the bending vibration band of $\mathrm{H}-\mathrm{O}-\mathrm{H}$ was at $1627.5 \mathrm{~cm}^{-1}$. The evident absorption band formed at $989.9 \mathrm{~cm}^{-1}$ indicates that the active components of catalysts exist in the form of $\mathrm{Mo}=\mathrm{O}$. Besides, with the increase in $\mathrm{MoO}_{3}$ contents, the bands became sharper and intenser. The results of FT-IR are in accordance with literatures about $a-\mathrm{MoO}_{3}$ [20].

\subsubsection{X-ray diffraction}

The X-ray diffraction technique has been widely used for the determination of crystalline phases in physics, chemistry, material science and other engineering technology [21]. The XRD patterns of molybdenum-based catalysts are presented in Figure 2. As shown in Figure 2 (a)-(e), $\mathrm{TiO}_{2}$ crystal has not changed after calcination. The peaks in good accordance with XRD spectra of $\mathrm{TiO}_{2}$-anatase crystal were detected at $2 \theta=25.55^{\circ}, 37.15^{\circ}, 48.35^{\circ}, 54.15^{\circ}, 55.35^{\circ}$, and $62.76^{\circ}$. The peak patterns were in good accordance with XRD spectra of $\mathrm{TiO}_{2}$-anatase crystal. There was no characteristic diffraction peak of $\mathrm{MoO}_{3}$ detected in the XRD pattern of Mo5 catalyst, which proved that the loading rate did not reach its dispersion threshold. In Mo5 catalyst the $\mathrm{MoO}_{3}$ crystals are small and

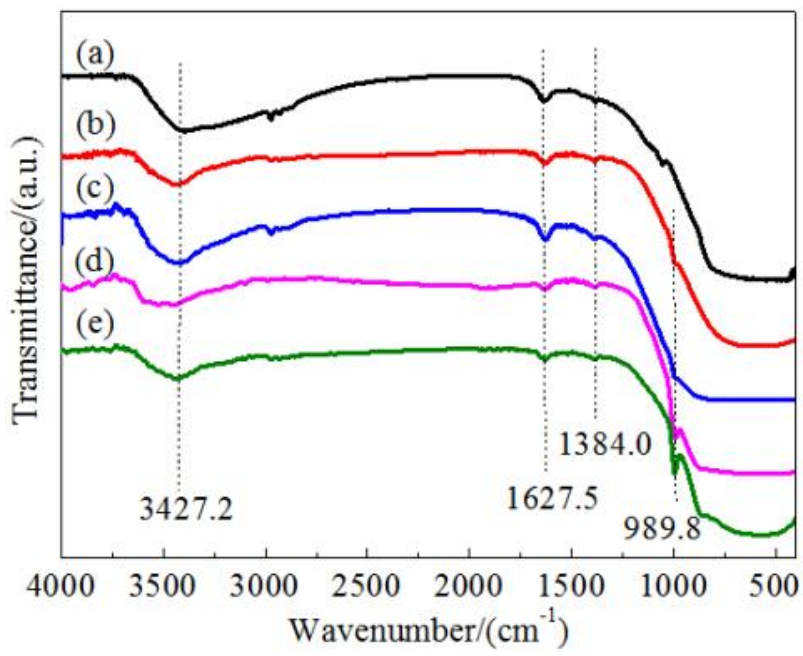

Figure 1. FT-IR spectra of $\mathrm{MoO}_{3} / \mathrm{TiO}_{2}$ catalysts (a: $\mathrm{TiO}_{2}$, b: Mo5, c: Mo10, d: Mo20, e: Mo40) amorphous, which is basically identical with literature [22]. When the loading rate reached $10 \%$, the characteristic diffraction peak of $\mathrm{MoO}_{3}$ appeared and large crystals formed, which confirmed that the loading content exceeded its dispersion threshold. Besides, with the increase in loading rate, the diffraction peaks of $\mathrm{MoO}_{3}$ are apparently characterized with narrow width, high peak and more crystallinity. Mo10, Mo20, and Mo40 all appeared the characteristic of orthorhombic crystal system $\left(\mathrm{\alpha}-\mathrm{MoO}_{3}\right)$. The main diffraction peaks at $12.72^{\circ}, 23.30^{\circ}, 25.66^{\circ}$, $27.28^{\circ}, 38.94^{\circ}$, and $67.55^{\circ}$, respectively, corresponds to the crystal plane (020), (110), (040), (021), (060) and (100) of $\mathrm{a}-\mathrm{MoO}_{3}$ (JCPDS card: 05-0508).

\subsubsection{Scanning electron microscope}

The SEM micrographs of $\mathrm{MoO}_{3} / \mathrm{TiO}_{2}$ catalysts with different loading rates are shown in Figure 3. The nano-scale carriers of $\mathrm{TiO}_{2}$ are spherical with an average size of $25-30 \mathrm{~nm}$. There are obvious pores and channels between particles. With the increase in $\mathrm{MoO}_{3}$ contents, the crystallinity and particle size increase. Meanwhile, bright and dense structures of Mo20 and Mo40 appeared. The octahedral crystals can be clearly observed, which were indicated by an arrow in Figure 3 (d) and (e). The particle size of Mo20 and Mo40 is greater than $100 \mathrm{~nm}$, which is in good accordance with precious characterization results.

\subsection{Activity of $\mathrm{MoO}_{3} / \mathrm{TiO}_{2}$ catalysts}

The activity of catalysts for soot oxidation was tested in a loose contact state, which was close to the real operation. TG and DTG data of

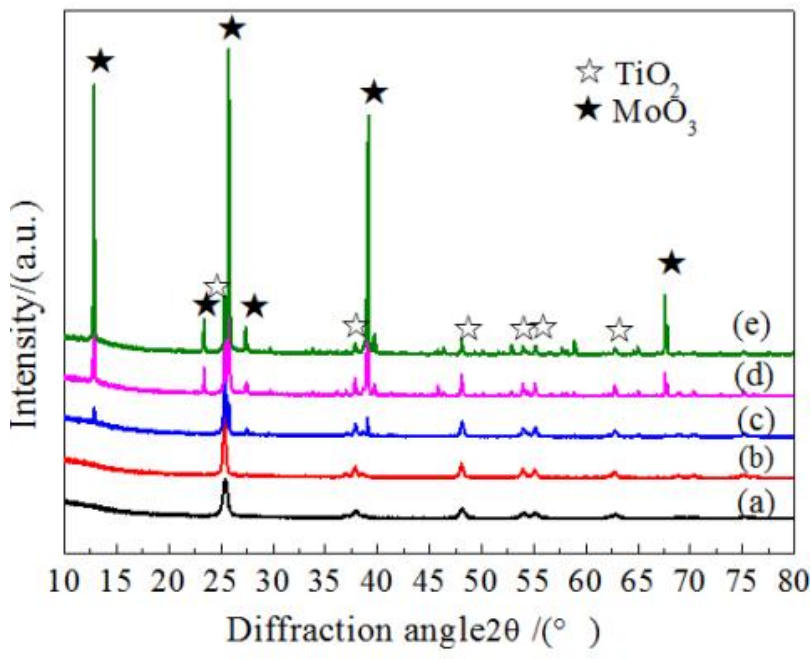

Figure 2. XRD spectra of $\mathrm{MoO}_{3} / \mathrm{TiO}_{2}$ catalysts (a: $\mathrm{TiO}_{2}$, b: Mo5, c: Mo10, d: Mo20, e: Mo40) 
soot with $\mathrm{MoO}_{3} / \mathrm{TiO}_{2}$ catalysts with various loading rates are shown in Figure 4 . The detailed characteristic parameters of soot oxidation are listed in Table 2. The light-off temperature $\left(T_{i}\right)$ is defined as the temperature at which the initial $5 \%$ of sample weight is lost. The peak temperature $\left(T_{p}\right)$ points to the temperature of maximum weight loss rate. The burnout temperature $\left(T_{f}\right)$ represents the temperature of the end of soot oxidation. The characteristic temperatures of $T_{i}, T_{p}$, and $T_{f}$ were reduced obviously, which demonstrates the desirable activities of $\mathrm{MoO}_{3}$ catalysts with various loading rates. This distinct performance of $\mathrm{MoO}_{3}$ catalysts may result from its low melting point, which can enhance the surface mobility obviously. With the increase of temperature, the active $\mathrm{MoO}_{3}$ gradually melted and infused soot, which provided more active sites and then helped to accelerate soot oxidation. Meanwhile, the $\mathrm{MoO}_{3}$ in orthorhombic phase is thermodynamic stable at high temperature, which ensures $\mathrm{MoO}_{3}$ cannot transform into other types easily $[20,23]$. Besides, with the unique twodimensional layered structure, it is easy for $\mathrm{MoO}_{3}$ to promote the oxidation reaction by separating a part of oxygen atoms.

From Figure 4, it can be concluded that TG and DTG profiles of soot with catalysts gradually shift to lower temperature and the characteristic temperatures were decreased with the increase in $\mathrm{MoO}_{3}$ contents. Compared with

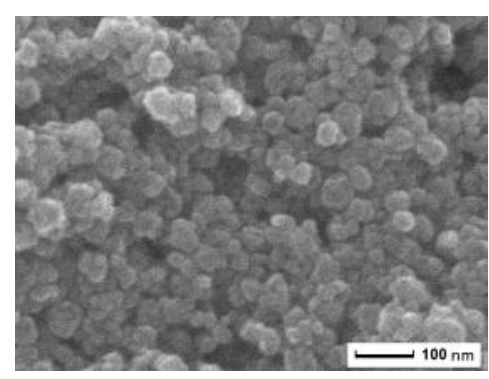

a. $\mathrm{TiO}_{2}$

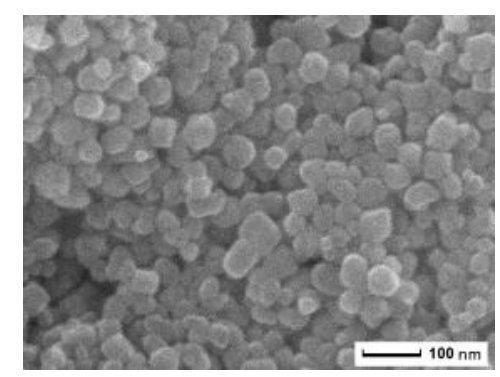

b. Mo5

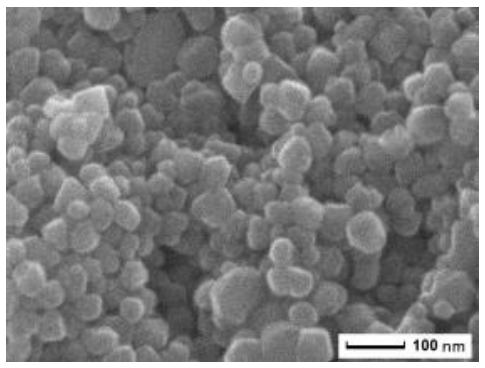

c. Mo10

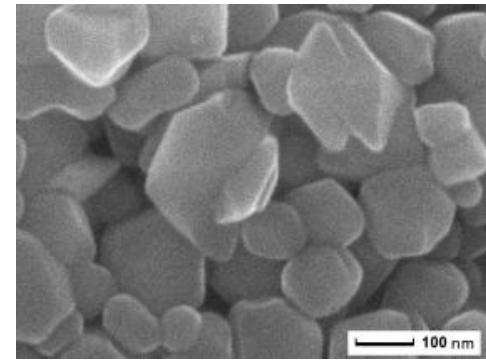

d. Mo20

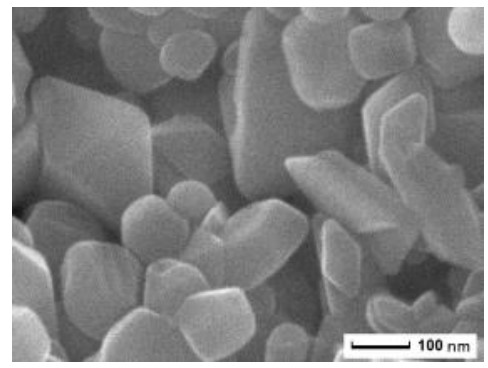

e. Mo40

Figure 3. SEM images of $\mathrm{MoO}_{3} / \mathrm{TiO}_{2}$ catalysts

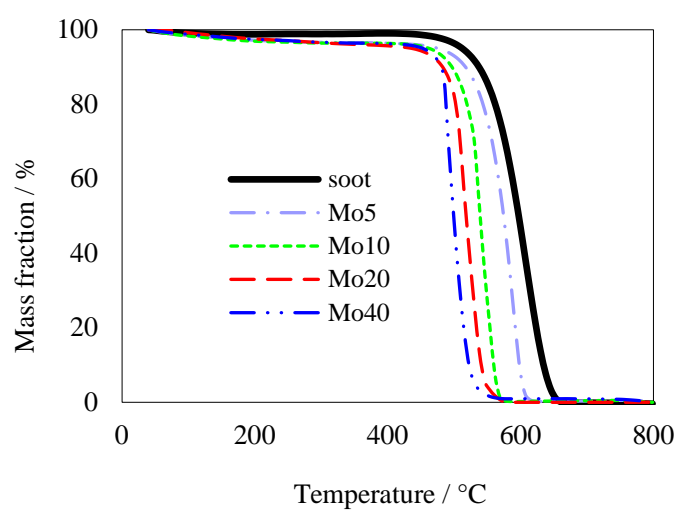

a. TG

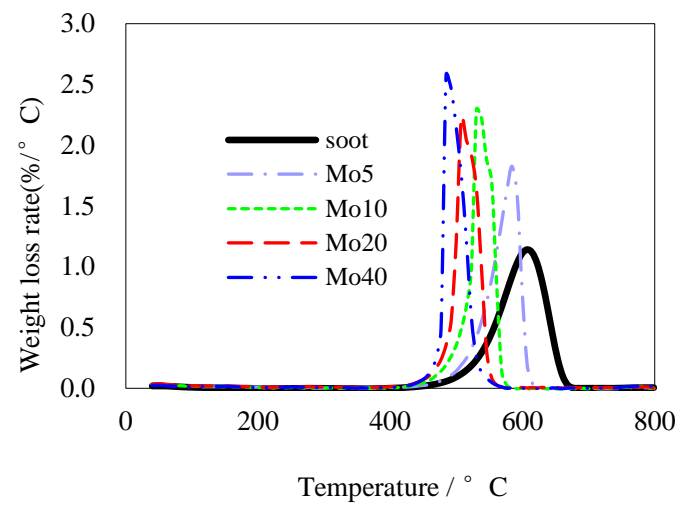

b. DTG

Figure 4. TG and DTG of soot with $\mathrm{MoO}_{3} / \mathrm{TiO}_{2}$ catalysts 
none catalyst, Mo40 manifests the highest catalytic activity and the characteristic temperatures $T_{i}, T_{p}$, and $T_{f}$ were decreased by $84.4{ }^{\circ} \mathrm{C}$, $122.6^{\circ} \mathrm{C}$, and $122.7^{\circ} \mathrm{C}$, respectively.

Furthermore, on the basis of BET analysis, the catalytic activity of $\mathrm{MoO}_{3} / \mathrm{TiO}_{2}$ did not increase with the specific surface area, which may be attributed to that the complex soot oxidation reaction takes place on the gas-solidsolid tri-phase interface [24]. The specific surface area of catalysts does not play a key role as usual.

\subsection{Pyrolysis kinetics}

The activation energy is supposed as the minimum energy needed to maintain a chemi-

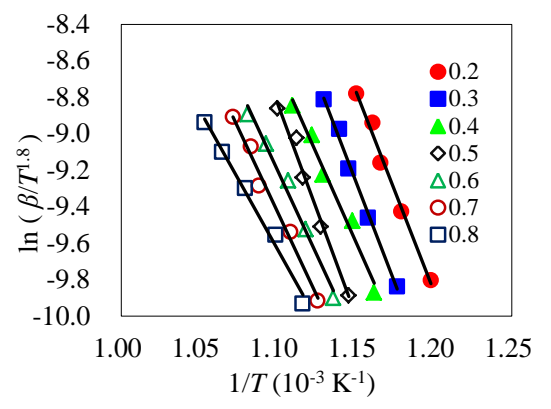

a. Soot

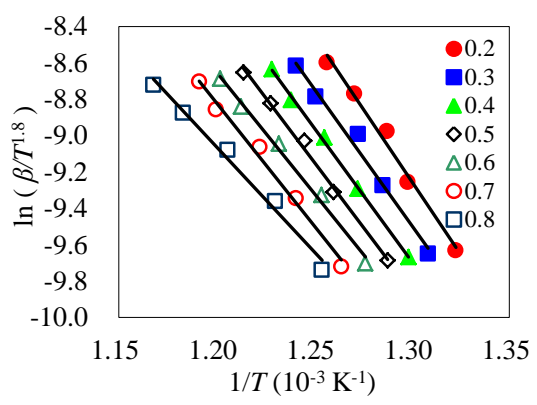

c. Mo10 cal reaction. It serves as an important indicator to evaluate the activity of catalysts due to its significance in the soot oxidation reaction. For each catalyst with various loading rate of $5 \%, 10 \%, 20 \%$, and $40 \%$, the $\ln \left(\beta / T^{1.8}\right)$ varying with $1 / T$ is plotted at the conversion rate of 0.2 , $0.3,0.4,0.5,0.6,0.7$, and 0.8 . According to the Starink method, the $\ln \left(\beta / T^{1.8}\right)$ and $1 / T$ are expected in a linear relationship, and then a group of fitted line, as shown in the Figure 5, were obtained by the discrete dots at each same conversion rate. The activation energy values, given in Table 3, were calculated. The square of the Pearson's correlation coefficients $\left(\mathrm{R}^{2}\right)$ were all greater than 0.98 , which proved that the equation has a high fitting degree.

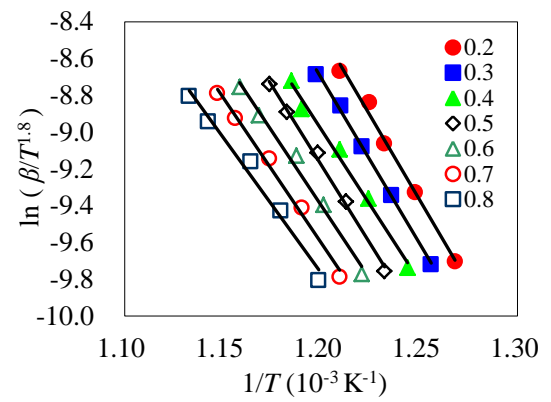

b. Mo5

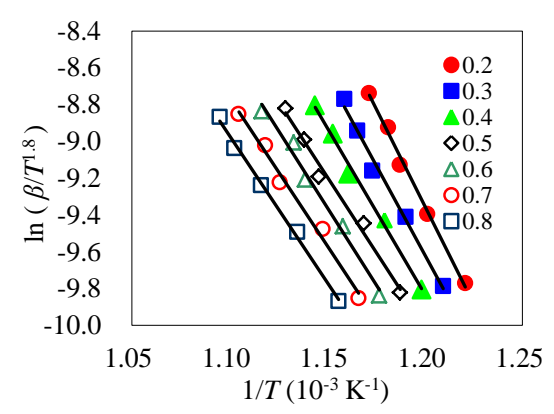

d. Mo20

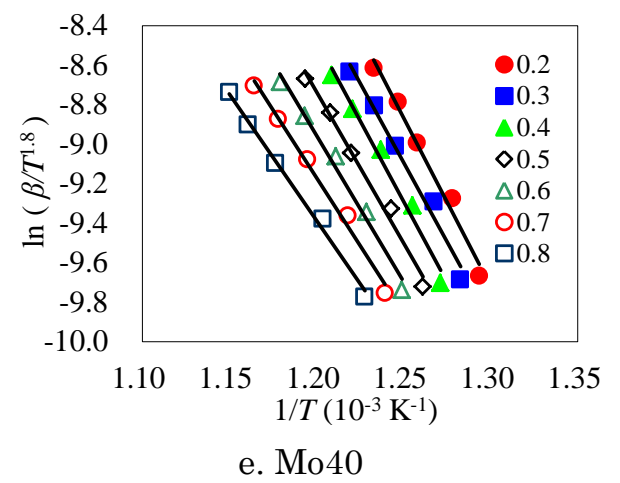

Figure 5. Linear relationship between $\ln \left(\beta / T^{1.8}\right)$ and $1 / T$ by the Starink method 
As shown in the Table 3, the activation energy of soot oxidation was decreased as the reaction was taken place in the catalytic circumstance [25-27]. This occurs because the soot oxidation starts at a lower temperature. With the rise in temperature, the reaction became easier and fierce. Besides, it was revealed that the activation energy was decreased continually with the increase in $\mathrm{MoO}_{3}$ contents from the Table 3. Among all the tested samples, the Mo40, owning the highest activity, demonstrates the lowest activation energy $\left(116.41 \mathrm{~kJ} \cdot \mathrm{mol}^{-1}\right)$ for soot oxidation, which fits well with the results shown in Figure 4.

\section{Conclusions}

The loading rates have great effects on the phase structure and catalytic activity of $\mathrm{MoO}_{3}$ catalysts. With the increase in $\mathrm{MoO}_{3}$ loading rate, the particle size of catalysts became larger, and both the specific surface areas and pore volumes of catalysts were reduced. The characteristic diffraction peaks of octahedral crystals $\left(\alpha-\mathrm{MoO}_{3}\right)$ appeared in the XRD pattern of catalysts when the loading rate of $\mathrm{MoO}_{3}$ exceeds $10 \%$. Based on the characteristic tem- peratures of soot oxidation for each sample, Mo40 manifests the highest activity compared with the non-catalyzed sample, of which the characteristic temperatures $T_{i}, T_{p}$, and $T_{f}$ were decreased by $84.4{ }^{\circ} \mathrm{C}, 122.6{ }^{\circ} \mathrm{C}$, and $122.7^{\circ} \mathrm{C}$, respectively. Based on the Starink method, the $\mathrm{MoO}_{3} / \mathrm{TiO}_{2}$ catalysts were characterized quantitatively in the soot oxidation. The activation energy for soot oxidation can be ranked as soot $<$ Mo5 $<$ Mo10<Mo20<Mo40, which fits well with the TG results. For the catalysts in this study, Mo40 owns the minimum activation energy $\left(116.41 \mathrm{~kJ} \cdot \mathrm{mol}^{-1}\right)$ of soot oxidation.

\section{Acknowledgement}

The authors wish to express their appreciation for the funds from the National Natural Science Foundation of China (No. 51376095 and No. 51506101), which supported this study.

\section{References}

[1] Wei, L., Ya, C., Wang, Q., Pan, W., Han, G . (2015). Combustion and emission characteristics of a turbocharged diesel engine using high premixed ratio of methanol and diesel fuel. Fuel, 140: 156-163.

Table 2. Characteristic parameters of soot oxidation under $\mathrm{MoO}_{3} / \mathrm{TiO}_{2}$ catalysts

\begin{tabular}{ccccc}
\hline Sample & $\begin{array}{c}\text { Ignition } \\
\text { temperature } \\
T_{i} /{ }^{\circ} \mathrm{C}\end{array}$ & $\begin{array}{c}\text { Temperature of } \\
\text { weight loss peak } \\
T_{p} /{ }^{\circ} \mathrm{C}\end{array}$ & $\begin{array}{c}\text { Burnout } \\
\text { temperature } \\
T_{f} /{ }^{\circ} \mathrm{C}\end{array}$ & $\begin{array}{c}\text { Maximum weight } \\
\text { loss rate } \\
/\left(\%{ }^{\circ} \mathrm{C}-1\right)\end{array}$ \\
\hline soot & 507.7 & 607.3 & 661.0 & 1.14 \\
Mo5 & 469.3 & 584.3 & 607.3 & 1.83 \\
Mo10 & 454.0 & 530.7 & 569.0 & 2.29 \\
Mo20 & 438.6 & 507.6 & 553.7 & 2.22 \\
Mo40 & 423.3 & 484.7 & 538.3 & 2.58 \\
\hline
\end{tabular}

Table 3. Activation energy of soot oxidation over $\mathrm{MoO}_{3} / \mathrm{TiO}_{2}$ catalysts

\begin{tabular}{cccccc}
\hline \multirow{2}{*}{$\begin{array}{c}\text { Conversion } \\
\text { rate } \alpha\end{array}$} & soot & Mo5 & Mo10 & Mo20 & Mo40 \\
\cline { 2 - 6 } & 181.67 & 175.42 & 150.10 & 141.39 & 132.57 \\
0.2 & 184.90 & 161.48 & 148.53 & 133.23 & 124.68 \\
0.3 & 159.62 & 149.86 & 136.65 & 135.55 & 121.59 \\
0.5 & 192.65 & 135.25 & 142.42 & 126.68 & 117.90 \\
0.6 & 153.38 & 138.75 & 133.28 & 122.91 & 110.48 \\
0.7 & 151.78 & 132.80 & 131.01 & 113.41 & 111.96 \\
0.8 & 127.21 & 131.96 & 122.35 & 106.11 & 95.69 \\
\hline average & 164.46 & 146.50 & 137.76 & 125.61 & 116.41 \\
\hline
\end{tabular}


[2] Phelps, A., Kirby, K.W., Gregoire, D.J. (2011). Resistive heater geometry and regeneration method for a diesel particulate filter. US, US8043658.

[3] Araki, Y. (1998). Device for purifying the exhaust gas of a diesel engine: EP, US5711149 A.

[4] Toniolo, F.S., Barbosa-Coutinho, E., Schwaab, M., Leocadio, I.C.L., Aderne, R.S., Schmal, M., Pinto, J.C. (2008). Kinetics of the catalytic combustion of diesel soot with $\mathrm{MoO}_{3} / \mathrm{Al}_{2} \mathrm{O}_{3}$ catalyst from thermogravimetric analyses. Applied Catalysis A: General, 342(1-2): 87-92.

[5] Leocadio, I.C.L., Braun, S., Schmal, M. (2004). Diesel soot combustion on $\mathrm{Mo} / \mathrm{Al}_{2} \mathrm{O}_{3}$ and $\mathrm{V} / \mathrm{Al}_{2} \mathrm{O}_{3}$ catalysts: investigation of the active catalytic species. Journal of Catalysis, 223(1): 114-121.

[6] Braun, S., Appel, L.G., Schmal, M. (2005). Molybdenum species on alumina and silica supports for soot combustion. Catalysis Communications, 6(1): 7-12.

[7] Matarrese, R., Castoldi, L., Artioli, N., Finocchiob, E., Buscab, G., Lietti, L.. (2014). On the activity and stability of Pt-K/ $/ \mathrm{Al}_{2} \mathrm{O}_{3}$ LNT catalysts for diesel soot and NOx abatement. Applied Catalysis B: Environmental, 144(2): 789791.

[8] Neeft, J.P.A., Pruissen, O.P.V., Makkee, M., Moulijn, J.A. (1997). Catalysts for the oxidation of soot from diesel exhaust gases II. Contact between soot and catalyst under practical conditions 1. Applied Catalysis B Environmental, 12(1): 21-31.

[9] Rodríguez-Fernández, J., Oliva, F., Vázquez, R.A. (2011). Characterization of the diesel soot oxidation process through an optimized thermogravimetric method. Energy \& Fuels, 25(5): 2039-2048.

[10] Mohan, V.M., Hu, B., Wen, C. (2010). Enhancement of electrochemical properties of $\mathrm{MoO}_{3}$ nanobelts electrode using PEG as surfactant for lithium battery. Journal of Solid State Electrochemistry, 14(10): 1769-1775.

[11] Li, J., Liu, J., Ren, L., Zhao, Z., Chen, Y., Zhu, P., Wei, Y., Duan, A., Jiang, G. (2014). Selective oxidation of ethane to aldehydes over SBA-15 supported molybdenum catalyst. Journal of Energy Chemistry, 23(5): 609-616

[12] Feng, M. (2012). Review of Molybdenum Catalysts for Direct Synthesis of Mixed Alcohols from Synthesis Gas. Recent Patents on Catalysis, 1: 13-26.

[13] Martin, I., And, J.H.H., Hartland, G.V. (1998). Effect of Structure on Electron Transfer Reactions between Anthracene Dyes and $\mathrm{TiO}_{2}$ Nanoparticles. Journal of Physical Chemistry B, 102(47): 9508-9517.
[14] Sharma, H.N., Pahalagedara, L., Joshi, A., Suib, S.L., Mhadeshwar, A.B. (2012). Experimental study of carbon black and diesel engine soot oxidation kinetics using thermogravimetric analysis. Energy \& Fuels, 26(9): 5613-5625.

[15] Ozawa, T. (1965). A new method of analyzing thermogravimetric data. Bulletin of the Chemical Society of Japan, 38(11): 1881-1886.

[16] Kissinger, H.E. (1957). Reaction kinetics in differential thermal analysis. Analytical Chemistry, 29(11): 1702-1706.

[17] Boswell, P.G. (1980). On the calculation of activation energies using a modified Kissinger method. Journal of Thermal Analysis and Calorimetry, 18(2): 353-358.

[18] Starink, M.J. (1996). A new method for the derivation of activation energies from experiments performed at constant heating rate. Thermochimica Acta, 288(1/2): 97-104.

[19] Alben, J.O., Fiamingo, F.G. (1984). Fourier Transform Infrared Spectroscopy-Optical Techniques in Biological Research-3. Optical Techniques in Biological Research, 17(4): 133179.

[20] Diao, Z., Kwong, F.L., Li, J., Lian, J., Lai, K.T., Ng, D.H.(2012). Catalytic Activity of Biomorphic $\alpha-\mathrm{MoO}_{3}$ in the Degradation of Methyl Violet Dye. Environmental Engineering Science, 29(9): 860-865.

[21] Albers, A.P.F., Melchiades, F.G., Machado, R., Baldo, J.B., Boschi, A.O. (2002). A simple method for the characterization of clay minerals by X-ray diffraction. Cerâmica, 48(305): 34-37.

[22] Shi, W., Cai, X., Wei, J., Ma, J., Hu, T., Wu, N., Xie, Y. (2001). EXAFS study of molybdenum oxide on the structure $\mathrm{Al}_{2} \mathrm{O}_{3}$. Surface \& Interface Analysis, 32(1): 202-204.

[23] Varga, T., Moats, J.L., Ushakov, S.V., Navrotsky, A. (2007). Thermochemistry of $\mathrm{A}_{2} \mathrm{M}_{3} \mathrm{O}_{12}$ Negative Thermal Expansion Materials. Journal of Materials Research, 22(9): 2512-2521.

[24] Shangguan, W.F., Teraoka, Y., Kagawa, S. (1997). Kinetics of soot- $\mathrm{O}_{2}$, soot-NO and soot$\mathrm{O}_{2}$-NO reactions over spinel-type $\mathrm{CuFe}_{2} \mathrm{O}_{4}$ catalyst. Applied Catalysis B: Environmental, 12(2/3): 237-247.

[25] Tomašić, V., Brnardić, I., Jenei, H., Kosar, V., Zrnčević, S.. (2011). Combustion of active carbon as a model carbon material: Comparison of non-catalytic and catalytic oxidation. Chemical and Biochemical Engineering Quarterly, 25(3): 283-287. 
[26] Jelles, S.J., Krul, R.R., Makkee, M., Moulijn, J.A. (1999). The influence of NOx on the oxidation of metal activated diesel soot. Catalysis Today, 53(4): 623-630.
[27] Hernández, S., Blengini, G.A., Russo, N., Fino, D. (2012). Kinetic study of diesel soot combustion with perovskite catalysts. Industrial \& Engineering Chemistry Reasearch, 51(22): 7584-7589. 